 \\ What is a qualitative synthesis?
}

Correspondence to:

Kate Seers

RCN Research Institute, School

of Health \& Social Studies,

University of Warwick, CV4 7AL

Warwick, UK;

kate.seers@warwick.ac.uk

\section{Kate Seers}

If you want to inform your practice with answers to questions such as 'What is it like for people to suffer chronic pain?' or 'What are patients' understanding and experience of hypertension and taking medication, ${ }^{\text {, }}$ or 'What are older people's views about falling and taking part in a falls programme ${ }^{2}$ then what might you do? You could read individual research papers, but often there are many papers and they can be difficult to track down and access. A qualitative synthesis (sometimes called a qualitative systematic review) systematically searches for research on a topic, and draws the findings from individual studies together. Although systematic reviews of quantitative data are well established, for qualitative research, this is a fairly new field, and methods are still developing.

There are several different ways of carrying out a qualitative synthesis (for more details, see refs. $^{3-6}$ ). Noblit and Hare $^{7}$ describe two broad types of qualitative syntheses. First, integrated reviews, where data are aggregated or summarised, often using themes. Second, interpretative reviews, which as the name suggests, involve interpreting the data. From this inductive approach, new conceptual understandings can emerge, leading to development of a theory that explains and integrates the concepts. Dixon-Woods et $a l^{8}$ emphasise 'the concern is with generating concepts that have maximum explanatory value'. p. 37, pointing out that all types of synthesis involve some summary of data and some interpretation.

One type of interpretive qualitative synthesis is meta-ethnography. This was described by Noblit and Hare $^{7}$ and has recently been identified as the most widely cited method used in qualitative synthesis ${ }^{6}$. Metaethnography can be used with different qualitative methodologies, not just ethnography. The actual themes or concepts or metaphors as described by the authors of the original research become the data for the metaethnography. Studies are compared by looking at these concepts and how they relate to each other. You ask questions such as 'How does this concept in this study relate to concepts in another study'. The next step is 'translation'. This has been described as 'reinterpretation and transformation of the analytical and theoretical concepts provided by individual studies into one another ${ }^{3}$ p. 79. A line of argument is built up; having compared studies, what can now be said-are there new concepts or a new understanding leading to a new theory, only apparent when you have looked at key concepts from the studies and how they might be connected. For example, a qualitative synthesis on medicine taking identified 'resistance' as the concept that best helped understand lay responses to prescribed medicines. ${ }^{9}$

Another type of interpretative qualitative systematic review is Critical Interpretative Synthesis. ${ }^{8}{ }^{10}$ Key concepts come from qualitative studies and from quantitative studies that "explicitly allows the integration of qualitative and quantitative evidence through an interpretative process'. ${ }^{8}$ p. 39.

So a qualitative synthesis is a developing area. It can be useful in drawing together qualitative research, and often enables new understandings of the data to emerge. This ensures findings from primary research can contribute, through a qualitative synthesis, to a greater understanding of an area, which may be relevant to your practice.

Competing interests None.

\section{References}

1. Marshall IJ, Wolfe CDA, McKevitt C. Lay perspectives on hypertension and drug adherence: systematic review of qualitative research. BMJ 2012;344:e3953.

2. McInnes E, Seers K, Tutton L. Older people's views in relation to risk of falling the need for intervention: a meta-ethnography. J Adv Nurs 2011;67:2525-36.

3. Pope C, Mays N, Popay J. Synthesising qualitative and quantitative health evidence. A guide to methods. Maidenhead: McGraw Hill Open University Press, 2007.

4. Sandelowski M, Barroso J. Handbook for synthesising qualitative research. New York: Springer, 2007.

5. Barnett-Page E, Thomas J. Methods for the synthesis of qualitative research: a critical review. ESRC National Centre for Research Methods. NCRM Working Paper Series, Number (01/09) 2. 2009. http://eprints.ncrm.ac.uk/690/ (accessed 20 Jul 2012).

6. Campbell R, Pound P, Morgan M, et al. Evaluating meta-ethnography: systematic analysis and synthesis of qualitative research. Health Technol Assess 2011;15:

7. Noblit G, Hare R. Meta-ethnography: synthesising qualitative studies. Qualitative Research Methods Series 11. California: Sage Publications, 1988.

8. Dixon-Woods M, Bonas S, Booth A, et al. How can systematic reviews incorporate qualitative research? A critical perspective. Qual Health Res 2006b:6:27-44.

9. Britten N, Campbell R, Pope C, et al. Using meta-ethnography to synthesise qualitative research: a worked example. $J$ Health Serv Res Policy 2002;7:209-15.

10. Dixon-Woods M, Cavers D, Agarwal S, et al. Conducting critical interpretative synthesis of the literature in access to health-care by vulnerable groups. BMC Res Methodol 2006a;6:35. 